\title{
HUBUNGAN TINGKAT PENGETAHUAN IBU TENTANG PAUD DENGAN KEIKUTSERTAAN ANAK PADA PAUD \\ DI DESA KARANGBANGUN JUMAPOLO KABUPATEN KARANGANYAR
}

\author{
Oleh : \\ Lilik Sriwiyati ${ }^{1}$, Endang Dwi Ningsih ${ }^{2}$, Lusiana Ambarningrum ${ }^{3}$
}

\begin{abstract}
Background Knowledge comes from learning, it occurs when a person sensed toward an object. Knowledge or cognitive ability is a very important domain affecting someone's behaviour (overt behavior). The participation in children in Early Childhood Education Programs is affected by their parent's knowledge.

Research purpose of this research is to seek the relation between mother's knowlegde level of Early Childhood Education Programs with the children's participation in Early Childhood Education Programs at Karangbangun Village, Karanganyar Regency.

Methods This research is a relational study and use cross sectional method. This research has two variables, the first variable is mother's knowledge level of Early Childhood Education Programs as a independent variable and the second variable is children's participation as a dependent variable. The samples were 30 responden selected by using total sampling method. Collecting data use questionaire paper. Data analysis use Chi square Test with $p 0,05$.

Results of this research are the children's participation is $25 \%$ on whose mother's knowlegde level considered as average and $78,57 \%$ on whose mother's knowlegde level considered as high. Statistical test use Chi Quadrat with the result $p=0,003$.

The conclusion of this research is that there is a relation between mother's knowlegde level of Early Childhood Education Programs with the children's participation in Early Childhood Education Programs at Karangbangun Village, Karanganyar Regency.
\end{abstract}

Keyword: Knowlegde of Early Childhood Education Programs and children's participation in Early Childhood Education Programs

\section{PENDAHULUAN}

Pengetahuan merupakan hasil tahu, dan ini terjadi setelah orang melakukan penginderaan terhadap suatu objek tertentu. Pengindraan terjadi melalui pancaindra manusia, yakni indra penglihatan, pendengaran, penciuman, rasa, dan raba. Sebagian besar pengetahuan manusia diperoleh melalui mata dan telinga. Pengetahuan atau kognitif merupakan domain yang sangat penting untuk terbentuknya

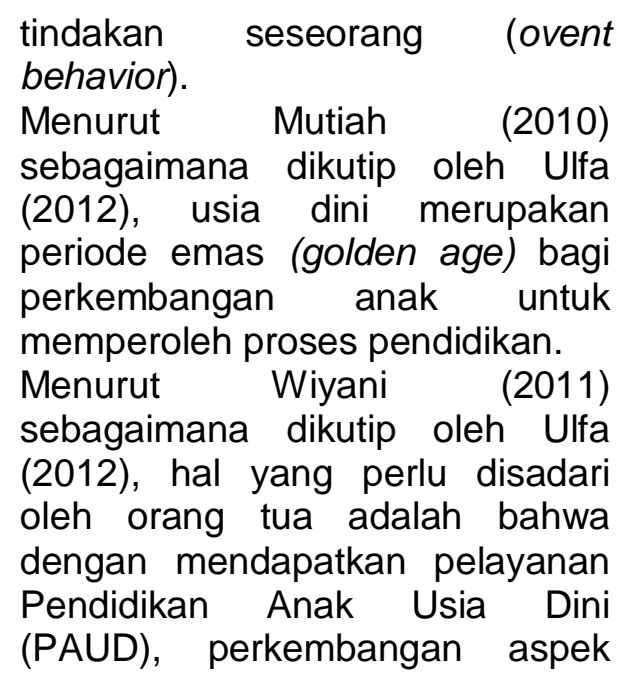


psikologis dan psikisnya akan meningkat dan berkembang dengan lebih optimal dibandingkan anak yang tidak melalui PAUD. Salah satu faktor yang menyebabkan lambatnya pertumbuhan anak usia dini adalah animo masyarakat atau kesadaran orang tua tentang urgensi PAUD yang rendah. Karena faktor kekurangpahaman, kesibukan, dan yang lainnya banyak orang tua yang melalaikan tahun-tahun penting pertama dalam kehidupan anak.

Berdasarkan data dari PAUD Lestari Desa Karangbangun jumlah murid yang terdaftar sebanyak 15 orang, sedangkan jumlah anak usia dini di Karangbangun sebanyak 30 orang. Survei dan pengamatan awal pada warga di Desa Karangbangun Jumapolo Kabupaten Karanganyar, diperoleh informasi beberapa pandangan ibu tentang PAUD yang berbeda-beda, ada yang mengatakan anak harus ikut PAUD supaya memiliki teman, ada yang merasa mengikutkan anak di PAUD tidak ada manfaatnya karena anak hanya bermain saja bahkan ada yang merasa sebagai pemborosan dan anak juga belum siap untuk sekolah.

\section{METODE PENELITIAN}

Penelitian ini menggunakan desain penelitian korelasi dengan pendekatan metode cross sectional. Korelasi adalah penelitian yang bertujuan mengetahui hubungan atau korelatif antar variabel dengan melibatkan dua atau lebih variabel. Sedangkan cross sectional merupakan rancangan penelitian yang pengukuran atau pengamatannya dilakukan secara simultan pada satu (sekali waktu). (Hidayat, 2008) Penelitian ini terdiri dari dua variabel yaitu tingkat pengetahuan ibu tentang PAUD sebagai variabel bebas (independent variable) dan keikutsertaan anak pada PAUD sebagai variabel terikat (dependent variable). Populasi dalam penelitian ini adalah keluarga yang mempunyai anak usia dini di Desa Karangbangun sejumlah 30 orang. Jumlah sampel dalam penelitian ini adalah 30 responden yang diambil dengan teknik sampling jenuh. Analisa statistik menggunakan uji Chi Square dengan $p=5 \%(0,05)$.

\section{HASIL PENELITIAN}

Berdasarkan penelitian yang telah dilakukan pada bulan Maret 2015 didapatkan karakteristik responden berdasarkan umur, tingkat pendidikan dan pekerjaan yaitu sebagai berikut :

\section{Tabel 1.}

Distribusi Frekuensi Karakteristik Demografi Responden

\begin{tabular}{lcc}
\hline Variabel & $\mathbf{f}$ & $\%$ \\
\hline Umur (Th) & & \\
\hline $16-25$ & 19 & 63,33 \\
\hline $26-35$ & 10 & 33,33 \\
\hline $36-45$ & 1 & 3,34 \\
\hline Jumlah & 30 & 100 \\
\hline Pendidikan & & \\
\hline $\begin{array}{l}\text { Tidak tamat } \\
\text { SD }\end{array}$ & 0 & 0 \\
\hline SD & 3 & 10 \\
\hline SMP & 13 & 43 \\
\hline SMA & 14 & 47 \\
\hline PT & 0 & 0 \\
\hline Jumlah & 30 & 100 \\
\hline Pekerjaan & & \\
\hline Swasta & 0 & 0 \\
\hline PNS & 0 & 0 \\
\hline Wiraswasta & 19 & 63 \\
\hline Lain-lain & 11 & 37 \\
\hline Jumlah & 30 & 100 \\
\hline & &
\end{tabular}

Tabel di atas menunjukkan bahwa berdasarkan umur responden paling banyak pada kelompok 
umur $16-25$ tahun yaitu berjumlah 19 responden (63.33\%), dan paling sedikit responden pada kelompok umur 36 - 45 tahun yaitu berjumlah 1 responden (3.34\%). Berdasarkan tingkat pendidikan mayoritas responden berpendidikan SMA yaitu sebanyak 14 (47\%). Sedangkan berdasarkan pekerjaan mayoritas responden bekerja sebagai wiraswasta, yaitu sebanyak 19 (63\%).

Berdasarkan hasil penilaian kuesioner didapatkan distribusi tingkat pengetahuan ibu tentang PAUD dan keikutsertaan anak pada PAUD sebagai berikut:

Tabel 2.

Distribusi Frekuensi Tingkat

Pengetahuan Responden tentang PAUD

\begin{tabular}{ccc}
\hline $\begin{array}{c}\text { Tingkat } \\
\text { Pengetahuan }\end{array}$ & $\mathbf{f}$ & $\%$ \\
\hline Tinggi & 14 & 46,66 \\
\hline Sedang & 16 & 53,34 \\
\hline Rendah & 0 & 0 \\
\hline Jumlah & 30 & 100 \\
\hline
\end{tabular}

Berdasarkan tabel di atas dapat diketahui bahwa sejumlah 14 (46.66\%) responden memiliki tingkat pengetahuan tinggi, 16 $(53.34 \%)$ responden memiliki tingkat pengetahuan sedang dan tidak ada responden yang memiliki tingkat pengetahuan rendah.

Tabel 3.

Distribusi Frekuensi

Keikutsertaan Anak pada PAUD

\begin{tabular}{lcc}
\hline $\begin{array}{c}\text { Keikutsertaan } \\
\text { Anak pada } \\
\text { PAUD }\end{array}$ & $\mathbf{f}$ & $\%$ \\
\hline lkut & 15 & 50 \\
\hline Tidak ikut & 15 & 50 \\
\hline Jumlah & 30 & 100 \\
\hline
\end{tabular}

Berdasarkan tabel di atas dapat diketahui bahwa dari 30 responden yang mempunyai anak usia dini, 15 (50\%) diantaranya mengikutsertakan anaknya pada PAUD dan 15 (50\%) lainnya tidak mengikutsertakan anaknya pada PAUD.

Hubungan tingkat pengetahuan ibu dengan keikutsertaan anak pada PAUD:

Tabel 4.

Hubungan Tingkat Pengetahuan lbu dengan Keikutsertaan Anak pada PAUD

\begin{tabular}{cccc}
\hline \multirow{2}{*}{$\begin{array}{c}\text { Tingkat } \\
\text { Pengetahuan }\end{array}$} & $\begin{array}{c}\text { Keikutsertaan } \\
\text { PAUD }\end{array}$ & Total \\
\cline { 2 - 4 } & Ikut & Tidak \\
\hline Sedang & 4 & 12 & 16 \\
\hline Tinggi & 11 & 3 & 14 \\
\hline Total & 15 & 15 & 30 \\
\hline Statistik & \multicolumn{3}{c}{$\begin{array}{c}\text { Chi Square } \\
\text { P }=0,003\end{array}$} \\
\hline
\end{tabular}

Berdasarkan hasil uji Chi-Square program SPSS versi 18.0 dengan p 5\% (0.05) diperoleh $p$ sebesar 0.003 sehingga nilai $p<0.05$, yang berarti $\mathrm{Ha}$ diterima dan $\mathrm{H}_{0}$ ditolak, sehingga dapat disimpulkan bahwa ada hubungan tingkat pengetahuan ibu tentang PAUD dengan keikutsertaan anak pada PAUD di Desa Karangbangun Kecamatan Jumapolo Kabupaten Karanganyar.

\section{PEMBAHASAN}

Berdasarkan hasil penelitian dapat dicermati bahwa responden yang memiliki tingkat pengetahuan tinggi sejumlah 14 (46.66\%), responden yang memiliki tingkat pengetahuan sedang sejumlah 16 (53.34\%), dan tidak ada responden yang memiliki tingkat pengetahuan rendah. Hal ini menunjukkan bahwa mayoritas ibu yang memiliki anak usia dini di 
Desa Karangbangun Kecamatan Jumapolo Kabupaten Karanganyar sudah tahu dengan pendidikan anak usia dini.

Menurut Notoatmodjo (2012) pengetahuan merupakan hasil tahu, dan ini terjadi setelah orang melakukan penginderaan terhadap suatu objek tertentu. Pengetahuan atau ranah kognitif merupakan domain yang sangat penting dalam membentuk tindakan seseorang (overt behavior).

Menurut Wawan dan Dewi (2010), faktor-faktor yang mempengaruhi pengetahuan antara lain adalah faktor internal yang meliputi : faktor pendidikan yang mana pada umumnya makin tinggi pendidikan seseorang makin mudah menerima informasi, faktor pekerjaan, faktor umur yang mana semakin cukup umur tingkat kematangan dan kekuatan seseorang akan lebih matang dalam berpikir dan bekerja.

Ditinjau dari data demografi yang telah diperoleh, dapat diketahui bahwa tingkat pendidikan responden mayoritas adalah SMA yaitu sebanyak 14 (47\%). Sedangkan berdasarkan pekerjaan mayoritas responden bekerja sebagai wiraswasta, yaitu sebanyak 19 (63\%). Wawan dan Dewi (2010) menyampaikan bahwa makin tinggi pendidikan seseorang makin mudah menerima informasi. Informasi tentang pendidikan anak usia dini saat ini sudah banyak tersebar baik secara langsung ataupun melalui media seperti televisi, radio, majalah dan lain-lain. Dengan didukung oleh tingkat pendidikan responden yang mayoritas SMA, maka memungkinkan responden dapat dengan mudah menerima informasi baru. Selain dari segi pendidikan, jika ditinjau dari segi umur diketahui bahwa mayoritas umur responden berada pada kelompok umur 16-25 tahun. Menurut Huclok (1998) sebagaimana dikutip oleh Wawan dan Dewi (2010), semakin cukup umur tingkat kematangan dan kekuatan seseorang akan lebih matang dalam berpikir dan bekerja. Umur responden tersebut mendukung kematangan berpikir dalam menentukan pendidikan untuk anaknya. Sedangkan apabila ditinjau dari segi pekerjaan, mayoritas responden bekerja sebagai wiraswasta. Hal ini memungkinkan responden mempunyai lebih banyak waktu untuk anak-anak mereka karena mereka tidak terikat oleh jam kerja. Beberapa hal di atas yang mendukung tingkat pengetahuan responden tentang PAUD berada pada kriteria sedang sampai dengan tinggi.

Menurut Suyadi dan Ulfah (2013) PAUD pada hakikatnya ialah pendidikan yang diselenggarakan dengan tujuan untuk memfasilitasi pertumbuhan dan perkembangan anak secara menyeluruh atau menekankan pada pengembangan seluruh aspek kepribadian anak. Secara institusional PAUD juga dapat diartikan sebagai salah satu bentuk penyelenggaraan pendidikan yang menitikberatkan pada peletakan dasar ke arah pertumbuhan dan perkembangan, baik koordinasi motorik (halus dan kasar), kecerdasan emosi, kecerdasan jamak (multiple intelligences) maupun kecerdasan spiritual. Menurut Yamin dan Sanan (2013) masa usia dini adalah masa yang sangat menentukan bagi perkembangan dan pertumbuhan anak selanjutnya karena merupakan masa peka dan masa emas dalam kehidupan anak. Hal ini mengisyaratkan bahwa semua pihak perlu memahami akan 
pentingnya masa usia dini untuk optimalisasi pertumbuhan dan perkembangan. Masa ini merupakan masa yang tepat bagi peletakan dasar-dasar pengembangan kemampuan fisik, bahasa, sosial-emosional, konsep diri, seni, moral dan nilai-nilai agama. Sehingga upaya pengembangan seluruh potensi anak usia dini harus dimulai agar pertumbuhan dan perkembangan anak tercapai secara optimal.

Berdasarkan pemaparan teori di atas dapat diketahui bahwa masa usia dini adalah masa emas yang sangat menentukan pertumbuhan dan perkembangan anak selanjutnya. Sehingga sangat diperlukan pendidikan anak usia dini dengan tujuan untuk memfasilitasi pertumbuhan dan perkembangan anak secara menyeluruh.

Hasil tabulasi silang tingkat pengetahuan ibu dengan keikutsertaan anak pada PAUD menunjukkan hasil bahwa terdapat 16 ibu yang memiliki tingkat pengetahuan sedang, dimana 4 (25\%) diantaranya mengikutsertakan anaknya pada PAUD dan 12 (75\%) lainnya tidak mengikutsertakan anaknya pada PAUD. Sedangkan ibu yang memiliki tingkat pengetahuan tinggi sejumlah 14, dimana 11 $(78,57 \%)$ diantaranya mengikursertakan anaknya pada PAUD dan 3 (21,43\%) lainnya tidak mengikutsertakan anaknya pada PAUD. Hal tersebut menunjukkan bahwa ibu yang memiliki tingkat pengetahuan tinggi lebih banyak mengikutsertakan anaknya pada PAUD dibandingkan dengan ibu yang memiliki tingkat pengetahuan sedang.

Analisa statistik hubungan tingkat pengetahuan ibu tentang PAUD dengan keikutsertaan anak pada PAUD menggunakan uji Chi-
Square program SPSS versi 18.0 dengan $\alpha=5 \%$ (0.05) diperoleh $p$ sebesar 0,003 . Karena nilai $p<$ 0.05, maka Ho ditolak dan $\mathrm{H}_{\mathrm{a}}$ diterima, sehingga penelitian ini menunjukkan bahwa ada hubungan antara tingkat pengetahuan ibu tentang PAUD dengan keikutsertaan anak pada PAUD di Desa Karangbangun Kecamatan Jumapolo Kabupaten Karanganyar.

\section{KESIMPULAN}

1. Tingkat pengetahuan ibu tentang PAUD pada kategori tinggi sejumlah 14 (46.66\%), kategori sedang sejumlah 16 $(53.34 \%)$ dan kategori rendah 0 (0\%).

2. Keikutsertaan anak pada PAUD sejumlah $15(50 \%)$ ikut dan sejumlah $15(50 \%)$ tidak ikut.

3. Hasil analisa statistik menggunakan uji Chi-Square dengan $\alpha=5 \%$ (0.05) diperoleh $\mathrm{p}$ sebesar 0.003 sehingga nilai $\mathrm{p}<0.05$, yang berarti ada hubungan tingkat pengetahuan ibu tentang PAUD dengan keikutsertaan anak pada PAUD.

\section{SARAN}

1. Bagi masyarakat

Diharapkan masyarakat dapat mengikutsertakan anaknya pada PAUD agar memfasilitasi tumbuh kembang anak.

2. Bagi orang tua

Diharapkan orang tua yang memiliki anak usia dini meningkatkan motivasi supaya dapat mengikutsertakan anaknya pada PAUD.

3. Bagi tenaga kesehatan

Diharapkan meningkatkan pemberian edukasi tentang masa emas anak dalam mencapai pertumbuhan dan perkembangan yang optimal.

4. Bagi peneliti selanjutnya 
Diharapkan

dapat menggunakan hasil penelitian ini sebagai data awal dalam melakukan selanjutnya.

penelitian

\section{DAFTAR PUSTAKA}

Aisyah, Siti et al. Perkembangan dan Konsep Dasar Pengembangan Anak Usia Dini. Jakarta : Universitas Terbuka, 2011.

Hidayat, A. Aziz Alimul. Riset Keperawatan dan Teknik Penulisan IImiah. Edisi II. Jakarta: Salemba Medika, 2008.

Metode Penelitian
Keperawatan dan Teknik
Analisis Data. Jakarta: Salemba Medika, 2009.

Notoatmojo, Soekidjo. Kesehatan Masyarakat IImu dan Seni. Jakarta: Rineka Cipta, 2011.

Promosi Kesehatan dan Perilaku Kesehatan. Jakarta : Rineka Cipta, 2012.

Suyadi dan Maulidya Ulfah. Konsep Dasar PAUD. Bandung : PT Remaja Rosdakarya, 2013.

Wawan A. dan Dewi M. Teori dan Pengukuran Pengetahuan Sikap dan Perilaku Manusia. Yogyakarta: Nuha Medika, 2010.
Yamin, Martinis dan Jamilah Sabri Sanan. Panduan PAUD. Jakarta : Referensi, 2013.

Andriani. Hubungan antara Motivasi Orang Tua dalam Mendidik Anak melalui PAUD dengan Partisipasinya di PAUD Kasih Ibu. Diakses 17 Oktober 2014.

Ulfah, Maria. Pengaruh Pengetahuan lbu tentang PAUD TERHADAP Keikutsertaan Anak Usia 2-3 Tahun pada Pendidikan Anak Usia Dini Nonformal di Desa Kebonagung Kecamatan Kajen Kabupaten Pekalongan. Diakses 17 Oktober 2014.

1 Dosen AKPER Panti Kosala Surakarta

2 Dosen AKPER Panti Kosala Surakarta

3 Mahasiswa AKPER Panti Kosala Surakarta 